\title{
Insufficient Evidence for Routine Use of Thromboprophylaxis in Ambulatory Patients with an Isolated Lower Leg Injury Requiring Immobilization: Results of a Meta-Analysis
}

\author{
Roderik Metz', Egbert-Jan M.M. Verleisdonk', Geert J.M.G. van der Heijden²
}

\begin{abstract}
Background: There are no generally accepted guidelines for the prevention of venous thromboembolism (VTE) in ambulatory patients requiring immobilization after an isolated lower leg injury. Our objective was to evaluate the effectiveness and safety of pharmacological interventions for preventing VTE in these patients. Study Design: Meta-analysis of randomized controlled trials.

Materials and Methods: We searched PubMed/ Medline, EMBASE and the Cochrane Central Register of Controlled Trials for trials with random allocation of thromboprophylaxis, notably low molecular weight heparin (LMWH) versus no prophylaxis or placebo, in ambulatory patients with below-knee or lower leg (including the knee joint) immobilization. Outcome was analyzed using MIX to calculate the pooled risk ratio/ relative risk (RR) for each outcome, along with its $95 \%$ confidence interval (CI).

Results: The RR of asymptomatic deep vein thrombosis (DVT) was 0.66 (95\% Cl 0.44; 1.02) for below-knee immobilization and 0.51 ( $95 \% \mathrm{Cl} 0.37 ; 0.70$ ) for lower leg immobilization. Low molecular weight heparin versus no prophylaxis or placebo was evaluated. The incidence of symptomatic DVT and PE was too low to show any statistically significant difference between thromboprophylaxis and controls in both groups. Although only one adverse bleeding event was considered to be major, the RR for any adverse bleeding event was 1.94 (95\% Cl 1.03; 3.67).

Conclusion: There is insufficient evidence to warrant routine use of thromboprophylaxis in ambulatory
\end{abstract}

patients with below-knee or lower leg immobilization after an isolated lower leg injury. The incidence of symptomatic VTE is too low to show a relevant clinical benefit from thromboprophylaxis.

\section{Key Words}

Lower leg · Immobilization ·

Thromboprophylaxis - Thrombosis .

Low molecular weight heparin

Eur J Trauma Emerg Surg 2009;35:169-75

DOI $10.1007 / \mathrm{s} 00068-008-8015-y$

\section{Background}

Venous thromboembolism (VTE) is a common complication in hospitalized bed-ridden patients after major trauma and after hip arthroplasty [1, 2]. Thromboprophylaxis is therefore provided in most of these patients. However, to date there are no generally accepted recommendations for the prevention of VTE in ambulatory patients requiring below-knee or lower leg (i.e., including the knee joint) immobilization after an isolated lower leg injury. The reported incidence of symptomatic deep vein thrombosis (DVT) after lower leg injury varies substantially, from $0.22 \%$ in patients operated on for foot or ankle injuries [3] to $7.6 \%$ after surgical treatment of Achilles tendon ruptures [4]. In a large cohort of nonsurgical isolated limb injuries treated with belowknee immobilization, an incidence of $1.0 \%$ was found [7]. At the Seventh ACCP Conference on Anti-

\footnotetext{
'Department of Surgery, Erasmus Medical Centre, Diakonessenhuis Utrecht, Rotterdam, The Netherlands,

${ }^{2}$ University Medical Centre Utrecht, Utrecht, The Netherlands.
} Published Online: December 8, 2008 
thrombotic and Thrombolytic Therapy, it was suggested that thromboprophylaxis should not be used in patients with isolated lower leg injuries, since it is uncertain whether prophylaxis similarly reduces the risk of clinically important VTE, or is cost-effective [6]. A quantitative analysis of results from randomized trials was not presented. The results of a survey of current practice on the use of thromboprophylaxis during lower leg immobilization in the United Kingdom showed substantial variation among physicians, and most of them were not aware of any existing guidelines in this regard [7]. Therefore, a critical analysis of the literature is warranted, considering that below-knee/lower-leg immobilization is frequently used in the treatment of Achilles tendon ruptures, ligament sprains and lower leg fractures. In this meta-analysis, we assess the effectiveness and safety of pharmacological interventions for preventing DVT or pulmonary embolism (PE) in patients with below-knee/lower-leg immobilization due to a cast or brace after an isolated lower leg injury.

\section{Materials and Methods}

\section{Search Strategy to Identify Studies}

The following electronic databases were searched: PubMed, from 1966 to July 2007; EMBASE, from 1980 to July 2007; The Cochrane Central Register of Controlled Trials (Clinical Trials). We constructed a topical search filter for PubMed and combined this topical search filter with the broad, sensitive PubMed clinical query for treatment. We also constructed a topical search filter for EMBASE (appendix). In the Cochrane Central Register of Controlled Trials, we searched for "leg injuries" and "thrombosis." We also searched the reference lists of the studies that were identified. There were no restrictions on language. If the inclusion criteria were met, full text articles were obtained (Figure 1).

\section{Selection of Studies}

The titles and abstracts of the retrieved records were checked by RM. Selection of records was based on the following criteria: the records relate to (1) clinical trials with (2) random allocation of pharmacological thromboprophylaxis (e.g., heparin, low molecular weight heparin, coumarins and antiplatelet treatment) in (3) ambulatory patients over 16 years old with (4) belowknee or lower leg (i.e., including patients with immobilized knee joints) immobilization after an isolated lower leg injury in which (5) the outcomes were DVT

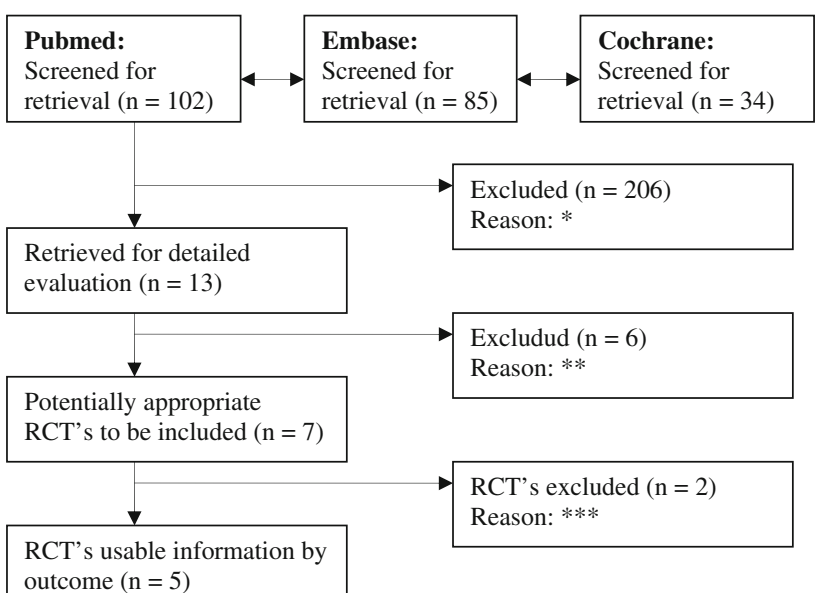

Figure 1. Flow diagram representing the search for and selection of trials. *No lower leg immobilization/injuries, no ambulatory patients/outpatients, nonpharmaceutical thromboprophylaxis, nonrandomized trials, overlap in databases. ${ }^{* *}$ Duplicate data, selection bias [23, 25-29]. ${ }^{* * *}$ Abstract only/insufficient data [20] or comparison of two interventions with no control group [22]. Two studies were retrieved by a manual reference search and were excluded after detailed evaluation [21, 24]

and PE. The selection was cross-checked by GH. Any disagreements were resolved by a third author (EV).

\section{Quality Assessment}

The methodological quality of the trials included was graded on six items, notably: randomization, concealment of allocation, blinding of treatment and endpoints, dropouts and completeness of data $[10,11]$ (Table 1).

\section{Data Extraction}

The number of events and the number of patients randomized for each treatment group in each trial were extracted. Events included: prevention of proximal and distal DVT by both clinical and diagnostic procedures, i.e., venography or duplex/ultrasound; PE diagnosed by V/Q lung scan, spiral computer tomography (CT), pulmonary angiography or autopsy; death related to embolic events. In addition, data on adverse events were extracted, notably for major bleeding (i.e., required transfusion of red blood cells or surgical interventions) and minor bleeding (i.e., did not meet the major criteria for intervention and bleeding-related death). Data on baseline characteristics (i.e., risk factors for thrombosis $[5,10]$ and intervention characteristics such as administration, dosage and duration) were also extracted (Table 2, 3). Data extraction was performed by one reviewer (RM) and cross-checked by 
Table 1. Quality assessment of the included randomized clinical trials. (+: Reported to be performed; -: reported as not being performed; ?: not reported/unknown. Missing data on DVT, obtained by a diagnostic procedure: +: reported and <10\%; -: not reported or reported and >10\%).

\begin{tabular}{|c|c|c|c|c|c|c|}
\hline Study & Randomization & $\begin{array}{l}\text { Concealment } \\
\text { of allocation }\end{array}$ & $\begin{array}{l}\text { Blinding of } \\
\text { treatment }\end{array}$ & $\begin{array}{l}\text { Blinding of } \\
\text { outcome }\end{array}$ & Withdrawals & $\begin{array}{l}\text { Missing } \\
\text { data }\end{array}$ \\
\hline Jorgensen [12] & + & $?$ & - & + & + & - \\
\hline Kock [13] & + & $?$ & - & - & + & - \\
\hline Kujath [14] & + & $?$ & - & - & + & - \\
\hline Lapidus [4] & + & $?$ & + & + & + & - \\
\hline Lassen $[15]$ & + & + & + & + & + & - \\
\hline
\end{tabular}

Table 2. Available baseline characteristics of the patients analyzed (pooled).

\begin{tabular}{lll}
\hline Baseline characteristics (pooled) & LMWH & No prophylaxis \\
\hline$N$ & 719 & 716 \\
Male & $405(56 \%)$ & $430(60 \%)$ \\
Smoking & $286(40 \%)$ & $299(42 \%)$ \\
Oral contraceptives & $47(7 \%)$ & $56(8 \%)$ \\
Previous DVT/venous thromboembolism & $17(2 \%)$ & $14(2 \%)$ \\
Varicose veins & $69(10 \%)$ & $88(12 \%)$
\end{tabular}

another (GH). Disagreements were resolved by consensus discussion.

\section{Statistical Analysis}

The data analysis was performed using MIX [11] in order to calculate the pooled risk ratio (RR) for each outcome, along with its $95 \%$ confidence interval (CI), according to the Mantel-Haenzel method. To overcome the unwarranted exclusion of studies without an event in both groups from the analysis, we added 0.001 events to the control group.

\section{Results}

Five trials met our search criteria [4, 12-15]. All five trials compared thromboprophylaxis by low molecular weight heparin to no prophylaxis or placebo. Patients selected in these studies had isolated lower leg injuries varying from ligament sprains to fractures. Three studies (Kock, Kujath, Lapidus) used ultrasound/duplex to screen for DVT, while two studies (Jorgensen, Lassen) used venography. Study characteristics are given in Table 3. Importantly, two studies reported on below-knee immobilization (Jorgensen, Lapidus), and three studies reported on lower leg immobilization (Kock, Kujath, Lassen). These last three studies included patients with an immobilized knee joint as well. Kock described the subgroup of patients with below- knee immobilization separately in his report, and these data were used for the analysis of VTE in below-knee immobilization as well.

\section{VTE in below-knee immobilization}

The relative risk (RR) of asymptomatic DVT (proximal and distal) in below-knee immobilization after an isolated lower leg injury (obtained by pooling data from three studies with a total of 587 patients) is 0.66 , with a $95 \%$ CI from 0.44 to 1.02 favoring prophylaxis (Jorgensen, Kock, Lapidus) (Figure 2). Low molecular weight heparin (LMWH) versus no prophylaxis or placebo was evaluated. The RR for asymptomatic proximal DVT alone (obtained by pooling data from three studies with a total of 640 patients) is 0.24 (95\% CI 0.05 ; 1.12) favoring prophylaxis (Jorgensen, Kock, Lapidus) (Figure 3). The RR of asymptomatic DVT in Achilles tendon rupture treatment (obtained by pooling data from two studies with a total of 167 patients) is 0.73 (95\% CI: 0.44; 1.21) favoring prophylaxis (Lapidus, Lassen). In the studies on below-knee immobilization, none of the participants suffered asymptomatic DVT or PE (Jorgensen, Kock, Lapidus). Therefore, an analysis of pooled data was not performed.

\section{VTE in lower-leg immobilization}

Kock, Kujath and Lassen reported on patients with lower leg immobilization. Pooling their results with those of Jorgensen and Lapidus (including 1,259 patients in total) resulted in a RR of asymptomatic DVT for lower leg immobilization of 0.51 (95\% CI: 0.37 ; 0.70) (Figure 4). As stated before, this RR concerns a mixed group of patients with ankle joint (below-knee) and/or knee joint immobilization.

The RR of symptomatic DVT in lower leg immobilization (obtained by pooling data from three studies with a total of 667 patients) is 0.28 (95\% CI 0.05 ; 1.69) favoring prophylaxis (Jorgensen, Lapidus, Lassen) (Figure 5). In the study by Lassen, clinical signs of DVT for each subgroup were described. In four out of 


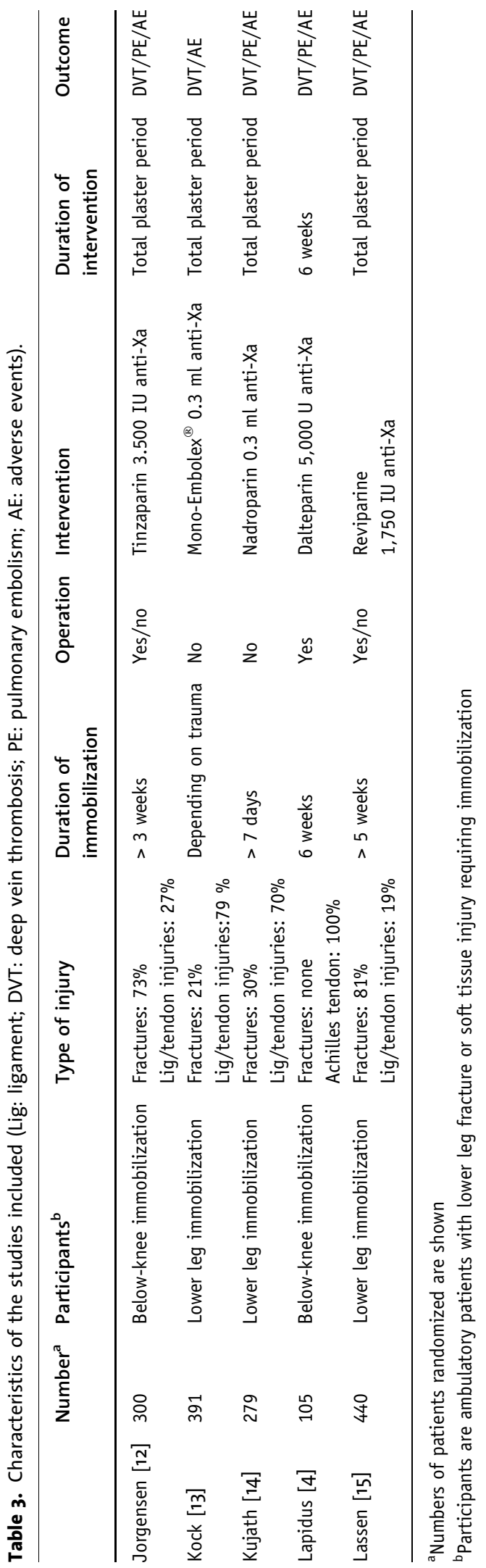

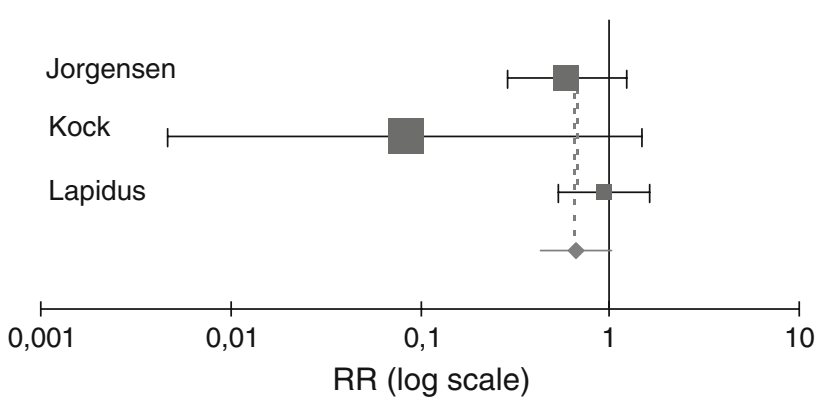

Figure 2. The effect of low molecular weight heparin on asymptomatic deep venous thrombosis in below-knee immobilization.

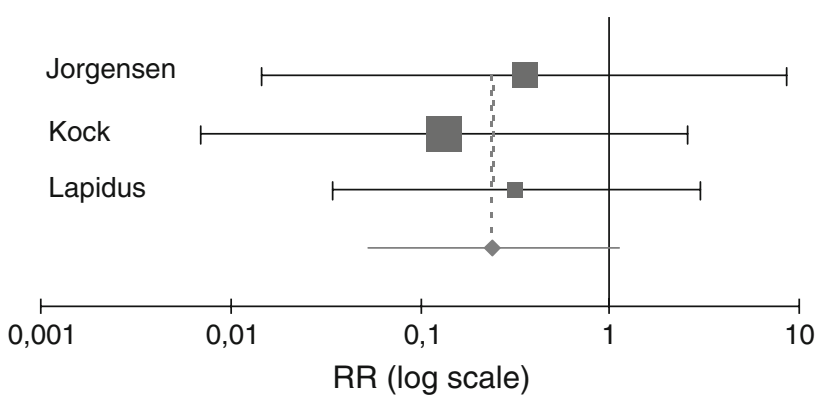

Figure 3. The effect of low molecular weight heparin on proximal asymptomatic deep venous thrombosis in below-knee immobilization.

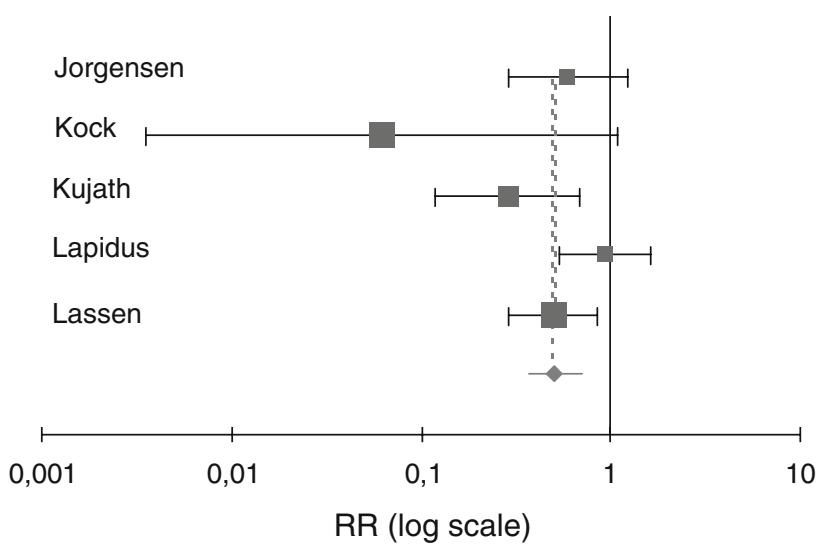

Figure 4. The effect of low molecular weight heparin on asymptomatic deep venous thrombosis in lower-leg immobilization.

11 patients with clinical suspicion of DVT, the diagnosis was confirmed by venography. All four patients were in the placebo group. In the studies by Jorgensen and Lapidus, none of the analyzed patients exhibited any clinical sings of DVT. Kock and Kujath did not report sufficiently on clinical DVT. The pooled absolute risk of symptomatic DVT in the control group is 1.2 versus $0 \%$ in the prophylaxis group. 


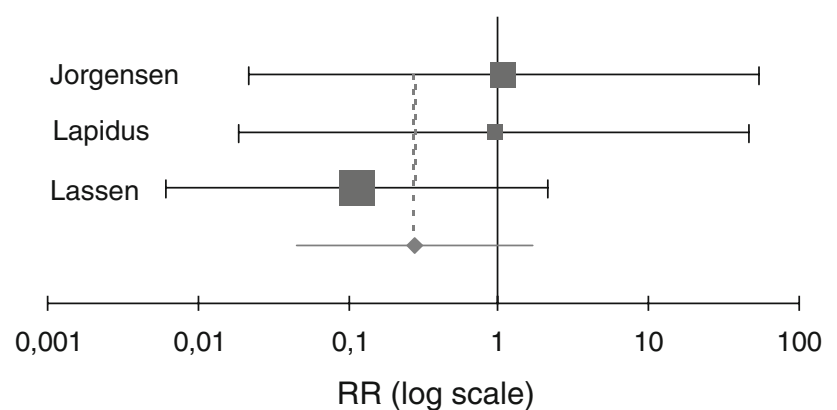

Figure 5. The effect of low molecular weight heparin on symptomatic DVT in lower leg immobilization.

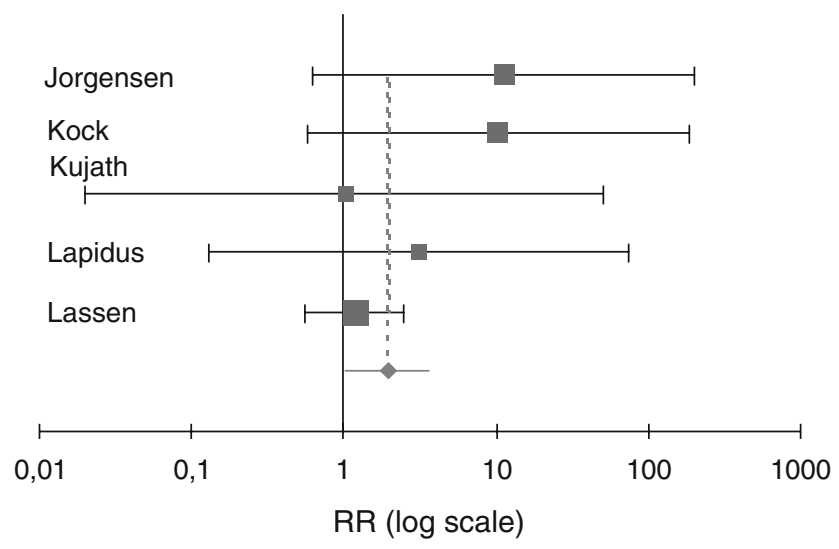

Figure 6. The effect of low molecular weight heparin on all adverse events in lower-leg immobilization.

PE was confirmed by ventilation-perfusion scan after clinical suspicion in two patients in the placebo group in the study by Lassen. In two studies, there was no clinical suspicion of $\mathrm{PE}$ in any of the patients (Jorgensen, Lapidus). Therefore, the RR for PE is 0.44 (95\% CI $0.06 ; 2.94)$ favoring prophylaxis, including three studies with a total of 843 patients (Figure 4).

Adverse events (in lower leg immobilization) Adverse events are reported in all studies (Jorgensen, Kock, Kujath, Lapidus, Lassen). The RR for any adverse event in lower leg immobilisation is 1.94 (95\% CI 1.03 ; 3.67) favouring no prophylaxis or placebo, including five studies with a total of 1,435 patients (Figure 6). One bleeding event (retroperitoneal bleed) described in the study by Lassen is considered to be major. All other bleeding events were minor (e.g., nose bleed, hematoma at injection site). Seven patients discontinued the allocated study medication (LMWH of placebo) due to minor bleeding; one due to metrorrhagia. None of the studies reported deaths. None of the studies reported any change in platelet count or signs of heparin-induced thrombopenia.

\section{Discussion}

The $34 \% \mathrm{RR}$ reduction in asymptomatic DVT in patients with below-knee immobilization using LMWH and the $76 \%$ RR reduction in potentially more dangerous proximal asymptomatic DVT are not statistically significant. The $49 \%$ RR reduction in asymptomatic DVT in patients with lower-leg immobilization is. However, the aim of thromboprophylaxis is to prevent symptomatic VTE (i.e., symptomatic DVT and post-thrombotic syndrome, PE and death by thromboembolic event). The incidence of symptomatic DVT after pooling data is $1.2 \%$ and is too low to show a statistically significant difference between groups. Much larger numbers are needed to clearly identify the benefit of prophylaxis (it was impossible to pool the results for symptomatic DVT and PE, as more patients were available for the outcome of PE). Still, asymptomatic DVT is accepted as a surrogate endpoint for VTE in hip and knee surgery [16, 17]. A parallel reduction in the relative risk of asymptomatic DVT and symptomatic VTE is found when thromboprophylaxis is used in these patient categories [19]. If this parallel reduction also exists in below-knee immobilization, a $49 \%$ reduction in a $1.2 \%$ absolute symptomatic DVT risk would mean treating over 150 patients to prevent one symptomatic DVT. The number that would be needed to be treated to prevent a PE would be much higher. But is the $1.2 \%$ symptomatic DVT risk realistic? In trials where DVT screening is used, knowledge of the results of these screening tests can affect the true incidence of symptomatic DVT (and VTE) due to diagnostic decision bias [16]. None of the studies included in our analysis reported the number of patients treated. Mizel's study did not use screening methods and found $\mathrm{a}<1 \%$ incidence of symptomatic DVT in patients after foot or ankle surgery with postoperative immobilization [3]. These results also suggest that the incidence of symptomatic DVT and (even more so) PE is probably very low. We cannot explain the high incidence of DVT reported by Lapidus, as the data from that investigation are unpublished [4]. The studies included provide indirect evidence for a large effect (RR reduction) of thromboprophylaxis on symptomatic VTE in lower leg immobilization. This effect of prophylaxis is not doubted; a clinically relevant effect of thromboprophylaxis on the incidence of symptomatic DVT or PE in patients with lower leg immobilization is questionable though, and probably even more so in below-knee immobilization. The incidence of symptomatic VTE seems too low to legitimize the routine use of prophylaxis. The results from our meta-analysis do show that thromboprophy- 
laxis using LMWH can be considered to be safe. Although thromboprophylaxis significantly increases the $\mathrm{RR}$ of adverse bleeding events, these events were all minor, except for one retroperitoneal bleed.

The results of this meta-analysis itself deserve some further considerations too. First, the number of studies included is limited, while the allocation of concealment and the completeness of the data analyzed are reported in an insufficient manner. There were several patients in the included studies for whom outcome could not be determined. The main reasons for missing outcome values were patients' refusal of venography or the technical impossibility of venography. $83 \%$ of the randomized patients were used in the analysis to calculate the RR for asymptomatic DVT, as the outcomes were unknown for the others. Most of these patients were not lost to follow-up and so were included in the analysis of risk of PE and adverse events.

Second, a variation in baseline risk across clinical trials included in a meta-analysis is common, and may have an impact on the benefits of treatment for individual patients [18]. The studies included varied in terms of the risk factors for thrombosis, such as type of injury, operation, hospitalization, and duration and type of immobilization. A rigid non-weight-bearing cast with knee joint immobilization is considered a bigger risk for the development of thrombosis than nonrigid weight-bearing below-knee immobilization [5]. Increased age and age-related (co)morbidities are considered to be risk factors as well [10], but age was consistent at baseline across studies. Furthermore, as no trials on the use of coumarins for the prevention of VTE were found, no conclusions can be drawn regarding the efficacy and safety of this antithrombotic agent. Finally, venography is considered the gold standard diagnostic test for DVT, but has largely been replaced by ultrasonographic modalities [19]. Kock, Kujath and Lapidus use ultrasound to measure outcome; if DVT is suspected, venography is performed. According to the study protocol, Kock verified all of the DVTs venographically. Kujath reported that 22 out of the 27 DVTs seen during compression ultrasound could be verified venographically. Lapidus verified all of the DVTs venographically except for two proximal DVTs, because duplex sonography was considered to exhibit high sensitivity and specificity for proximal DVT.

In conclusion, there is insufficient evidence for the routine use of thromboprophylaxis in ambulatory patients with below-knee or lower leg immobilization after an isolated lower-leg injury. Future studies should include large numbers of patients with a stratification of risk factors; only this would make it possible to find a selected patient group that can clearly benefit from pharmacological thromboprophylaxis during the immobilization of an injured leg.

\section{Acknowledgment}

We thank Professor Chr. van der Werken from the University Medical Centre Utrecht for his advice on improving our manuscript.

\section{References}

1. Geerts WH, Code KI, Jay RM, Chen E, Szalai JP. A prospective study of venous thromboembolism after major trauma. $\mathrm{N}$ Engl J Med 1994;331:1601-6.

2. Handoll HHG, Farrar MJ, McBirnie J, Tytherleigh-Strong G, Milne AA, Gillespie WJ. Heparin low molecular weight heparin and physical methods for preventing deep vein thrombosis and pulmonary embolism following surgery for hip fractures. Cochrane Database Syst Rev 2002;CDo00305.

3. Mizel MS, Temple HT, Michelson JD, Alvarez RG, Clanton TO, Frey CC, Gegenheimer AP, Hurwitz SR, Lutter LD, Mankey MG, Mann RA, Miller RA, Richardson EG, Schon LC, Thompson FM, Yodlowski ML. Thromboembolism after foot and ankle surgery. A multicenter study. Clin Orthop Relat Res 1998;348:180-5.

4. Geerts WH, Pineo GF, Heit JA, Bergqvist D, Lassen MR, Colwell CW, Ray JG. Prevention of venous thromboembolism: the Seventh ACCP Conference on Antithrombotic and Thrombolytic Therapy. Chest 2004;126(3 Suppl):338S-400S.

5. Batra S, Kurup H, Gul A, Andrew JG. Thromboprophylaxis following cast immobilisation for lower limb injuries-survey on current practice in the United Kingdom. Injury 2006;37:813-7.

6. Jadad AR, Moore RA, Carrol D, Jenkinson C, Reynolds DJ, Gavaghan DJ, McQuay HJ. Assessing the quality of reports of randomized clinical trials: Is blinding necessary? Control Clin Trials 1996;17:1-2.

7. Moher D, Cook DJ, Eastwood S, Olkin I, Rennie D, Stroup DF, QUOROM Group. Improving the quality of reports of metaanalyses of randomised controlled trials: the OUOROM statement. Quality of reporting of meta-analyses. Lancet 1999;354:1896-900.

8. Riou B, Rothmann C, Lecoules N, Bouvat E, Bosson JL, Ravaud P, Samana CM, Hamadouche $M$. Incidence and risk factors for venous thromboembolism in patients with nonsurgical isolated lower limb injuries. Am J Emerg Med 2007;25:502-8.

9. Samama MM. An epidemiologic study of risk factors for deep vein thrombosis in medical outpatients: the Sirius study. Arch Intern Med 2000;160:3415-20.

10. Bax L, Yu LM, Ikeda M, Tsuruta H, Moons KG. Development and validation of MIX: comprehensive free software for meta-analysis of causal research data. BMC Med Res Methodol 2006;6:50.

11. Jorgensen PS, Warming T, Hansen K, Paltved C, Vibeke Berg $H$, Jensen R, Kirchhoff-Jensen R, Kjaer L, Kerbouche N, LethEspensen P, Narvestad E, Rasmussen SW, Sloth C, Torholm C, Wille-Jorgensen P. Low molecular weight heparin (Innohep) as thromboprophylaxis in outpatients with a plaster cast: a venografic controlled study. Thromb Res 2002;105:477-80.

12. Kock HJ, Schmit-Neuerburg KP, Hanke J, Rudofsky G, Hirche H. Thromboprophylaxis with low-molecular-weight heparin in outpatients with plaster-cast immobilisation of the leg. Lancet 1995;346:459-61. 
13. Kujath P, Spannagel U, Habscheid W. Incidence and prophylaxis of deep venous thrombosis in outpatients with injury of the lower limb. Haemostasis 1993;23:20-6.

14. Lapidus $\sqcup$, Rosfors S, Ponzer S, Levander C, Elvin A, Larfars G, de Bri E. Prolonged thromboprophylaxis with dalteparin after surgical treatment of achilles tendon rupture: a randomized, placebo-controlled study. J Orthop Trauma 2007;21:52-7.

15. Lassen MR, Borris LC, Nakov RL. Use of the low-molecularweight heparin reviparin to prevent deep-vein thrombosis after leg injury requiring immobilization. $N$ Engl J Med 2002;347:726-30.

16. Kent DM, Hayward RA. Limitations of applying summary results of clinical trials to individual patients: the need for risk stratification. JAMA 2007;298:1209-12.

17. Goodacre S, Sampson F, Thomas S, van Beek E, Sutton A. Systematic review and meta-analysis of the diagnostic accuracy of ultrasonography for deep vein thrombosis. BMC Med Imaging 2005;5:6.

18. Gaudenak T, Kuderna H, Olbert F, Pelinka H, Schlag G. Proceedings: A randomized comparative study on early prophylactic treatment of thrombosis using heparin and high-molecular dextran following injuries of the lower-leg. Thromb Diath Haemorrh 1975;34:597.

19. Giannadakis K, Gehling $\mathrm{H}$, Sitter $\mathrm{H}$, Achenbach $\mathrm{S}$, Hahna $\mathrm{H}$, Gotzen L. Is a general pharmacologic thromboembolism prophylaxis necessary in ambulatory treatment by plaster cast immobilization in lower limb injuries? Unfallchirurg 2000;103:475-8.

20. Gehling H, Giannadakis K, Lefering R, Hessman M, Achenbach S, Gotzen L. Prospective randomized pilot study of ambulatory prevention of thromboembolism. 2 times $500 \mathrm{mg}$ aspirin (ASS) vs. clivarin 1750 (NMH). Unfallchirurg 1998;101:42-9.

21. Habscheid W, Spannagel U, Kujath P, Schindler G. Prevention of thrombosis with low molecular weight heparin in ambulatory patients with injury of the lower extremity: an ultrasound study. Vasa Suppl 1991;33:222-3.
22. Haentjens P. Thromboembolic prophylaxis in orthopaedic trauma patients: a comparison between a fixed dose and an individually adjusted dose of a low molecular weight heparin (nadroparin calcium). Injury 1996;27:385-390.

23. Kock HJ, Schmit-Neuerburg KP, Hanke J, Hakmann A, Althoff $M$, Rudofski G, Hirche H. Ambulatory prevention of thrombosis with low molecular weight heparin in plaster immobilization of the lower extremity. Chirurg 1993;64:483-91.

24. Kock HJ, Schmit-Neuerburg KP, Hanke J, Terwort A, Rudofsky G, Hirche $\mathrm{H}$. Implementing ambulatory prevention of thrombosis with low molecular weight heparin in plaster immobilization of the lower extremity. Unfallchirurg 1994;20:319-28.

25. Kock HJ, Schmit-Neuerburg KP, Hanke J, Hakmann A, Althoff $M$, Rudofski G. Ambulatory prevention of thrombosis with low molecular weight heparin in plaster immobilization of the lower extremity. Vasa Suppl 1992;35:105-6.

26. Kujath $P$, Spannagel $U$, Habscheid W. Thrombosis prevention in outpatients with lower limb injuries. Dtsch Med Wochenschr 1992;117:6-10.

27. Spannagel U, Kujath P. Low molecular weight heparin for the prevention of thromboembolism in outpatients immobilized by plaster cast. Semin Thromb Hemost 1993;19(Suppl 1):131-41.

\author{
Address for Correspondence \\ Roderik Metz \\ Department of Surgery \\ Erasmus Medical Centre \\ Postbus 2040 \\ 3000 CA \\ Rotterdam \\ The Netherlands \\ Phone $(+31 / 10)-7033619$ \\ e-mail: metz_r@hotmail.com
}

